\title{
The physical integration of a significant marine engineering package into the T23 Frigate
}

\author{
D G Dobbins, BSc (Hons), AMRINA* \\ *Naval Design Partnering, UK MoD, Bristol, UK; Seconded from Babcock International Group \\ *Corresponding Author. Email: daniel.dobbins@babcockinternational.com
}

\begin{abstract}
Synopsis
The Type 23 Frigate (T23) has been extended in-service well beyond its initial design life of 18 years, with some ships due to be over 35 years old when they leave service. To ensure the vessels remain effective \& available a T23 Life Extension (LIFEX) programme was set up to meet this revised End of Life (EOL). A significant element of this LIFEX and the focus of this paper is PGMU (Power Generation and MCAS Update).
\end{abstract}

\begin{abstract}
The aim of PGMU is to restore electrical power margins and to overcome equipment obsolescence. This requirement was set with the obvious constraint that new equipment must integrate with the existing ship and it's supporting systems without adversely affecting key operational characteristics.

Considered an Alteration \& Addition (A\&A) but the largest the T23 has ever seen, the project has encompassed the entire cradle to birth cycle and equipment is currently being fitted into the first of class with a plan to achieve sea trials in Q2 2019.
\end{abstract}

\begin{abstract}
PGMU will replace the most critical assets of a warship; its power generation system. It replaces the 4 diesel generators with higher power units, the replacement of the 2 motor generator sets that supply the 440v ship services, upgrades the switchboards as well as the Machinery Controls and Surveillance System (MCAS). Challenges have come in the form of structural limitations; stability management; signature management; physical integration and the re-designing of a legacy platform to new standards.

This paper builds on one that I presented at INEC 2016: "Facing the challenges of integration and physical constraints when replacing major equipment in old platforms". This edition will cover issues that have arisen in the later stages of the design and validation through into the integration for First of Class (FoC); HMS Richmond. It will concentrate on the naval architectural aspects of the project and will consider how they were managed whilst offering an overview of some of the key learning from experience (LFE) that has been gained.
\end{abstract}

Keywords: De-Risking; Design-and-Build; Naval-Architecture; LIFEX; Refit; T23-Frigate

\section{Introduction: The need for PGMU}

The Type 23 Frigates (T23) are nearing their End of Life (EOL). Their replacements, the Type 26 Frigates (T26) are not due to enter service until the mid-2020s and as such the last of the T23s will remain in service until at least 2035.

As the class of T23s have nearly doubled their 18year planned life, all margins are almost spent; to ensure that the class can continue to operate until their revised EOL; PGMU aims to restore Power Margins without adversely affecting other margins such as stability. Restoring the power margins for the class may also enable new and greater power-dense systems to be integrated into each ship. With the advent of Direct Energy Weapons (DEW) on the horizon for naval platforms, this update maintains the flexibility that might allow the class to carry out trails of this technology if required.

The need to upgrade the power generation of T23s stems from the fact that they were originally designed in the 80s as Anti-Submarine Warfare (ASW) platforms, operating in the cold climate of the North Atlantic / Iceland Faroes gap; they now find themselves operating as general purpose frigates in much warmer waters where their Diesel Generators (DG) are typically de-rated by $20 \%$. This is because neither the DGs or their cooling water systems were specified for the water temperatures being experienced. Figure 1 illustrates the Power Margin impact that PGMU will have on the class of T23s.

PGMU also comes at a very interesting time for the Royal Navy (RN), with similar projects following closely behind with the likes of the Power Improvement Plan (PIP) for Type 45 Destroyer (T45).

\section{Author's Biography}

Daniel's career started in the leisure yachting industry before joining Babcock International Group where he has now been employed for over 3 years. The last 2 years of this employment has seen Daniel on secondment to the Ministry of Defence's (MoD) Naval Design Partnering Team (NDP) as the PGMU Naval Architect. 


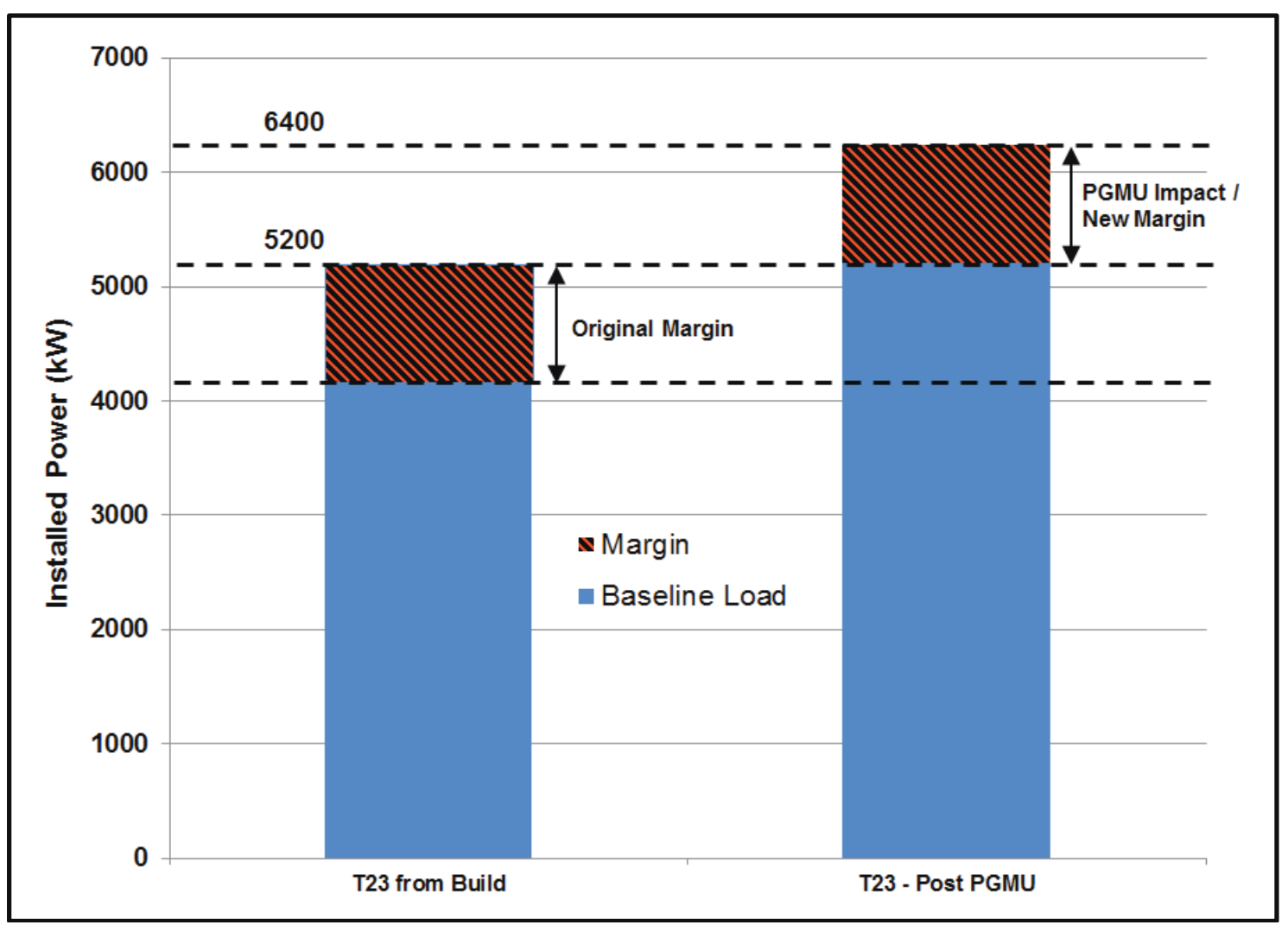

Figure 1 - PGMU Power Margin Impact

\subsection{The story so far...}

In May 2012 PGMU passed initial gate to begin the Assessment Phase (AP), Main Gate (MG) was achieved in November 2013. The contracts for the Original Equipment Manufacturers (OEM) of the major equipment units; MTU for the Diesel Generators (DG) \& Hitzinger for the Motor Generators MG were placed during the middle of 2015.

The PGMU project follows the traditional Concept-Assessment-Demonstration-Manufacture-In-ServiceDisposal (CADMID) cycle. It should be stressed that this is not just an equipment project; all Defence Lines of Development (DLODs) have to be considered alongside logistics, training \& operational changes.

Table 1 - PGMU CADMID Cycle Dates

\begin{tabular}{lrr}
\hline \multicolumn{1}{c}{ Phase } & Date of Start & Date to Conclusion \\
\hline Concept & March 2014 & June 2014 \\
Assessment & July 2014 & July 2017 \\
Detailed Design & March 2016 & October 2017 \\
Manufacture & November 2017 & August 2019 \\
$\begin{array}{l}\text { In-Service } \\
\begin{array}{l}\text { Disposal } \\
\text { (Decommissioning) }\end{array}\end{array}$ & Q2 2019 & 2030 \\
\end{tabular}

The project has opted for reliable Commercial Off-The-Shelf (COTS) equipment, to ensure suitability; this equipment has undergone the necessary testing in order to validate the systems to classification societies, the International Maritime Organisation (IMO) \& military standards - making changes to the design only where essential. 


\subsection{Team make-up}

The PGMU Project Team (PT) is based in MoD Abbey Wood and is supported technically by Naval Design Partnering (NPD). The NDP is an arm of Defence Equipment \& Support (DE\&S) to the MoD and is the Design Authority (DA) for the project. Babcock International is undertaking the installation of PGMU in Her Majesty's Naval Base (HMNB) Devonport as part of the T23 upkeep package. The IS has been developed under the Design Management Services (DMS) contract by a combined team contract from Babcock \& BAE, this is an unusual step but was originally envisaged as the only viable way to meet the timescale.

For contracting purposes PGMU was divided into 5 separate Lots:

Lot 1 - Diesel Generators (DG)

Lot 2 - Motor Generators (MG)

Lot 3 - Switchboards

Lot 4 - Machinery Control and Surveillance (MCAS)

Lot 5 - System Integration

\author{
MTU (Hitzinger Generators) \\ Hitzinger \\ Rolls Royce \\ Rolls Royce \\ Babcock International
}

\subsection{Spatial Impact}

The spaces and compartments affected by PGMU are depicted in Figure 1 below.

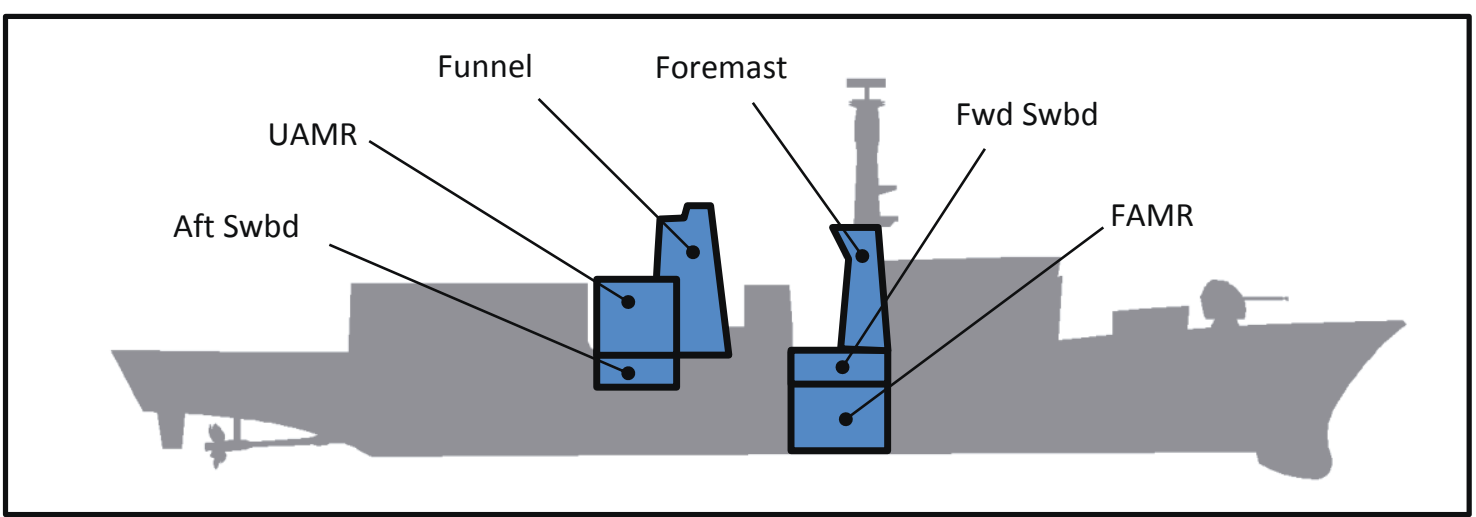

Figure 2 - Spaces affected by PGMU

\subsection{The Big Stuff}

PGMU centres around the fit of Lot $1 \& 2$ items, the specifications of which can be seen in Table 2.

Table 2 - Major Equipment Comparison

\begin{tabular}{lcc}
\hline & Current Equipment & Replacement Equipment \\
\hline DG Set $\boldsymbol{x} 4$ & Paxman (Valenta) & MTU (12V4000) \\
Output $(k W)$ & 1300 & 1600 \\
Speed $($ rpm) & 1200 & 1800 \\
Power Factor & 0.68 & 0.70 \\
\hline MG Set $\boldsymbol{x}$ 2 & Laurence Scott & Hitzinger \\
Output $(k W)$ & 945 & 1250 \\
Speed $($ rpm) & 1200 & 1200 \\
Power Factor & M:0.89, G:0.80 & M:0.91, G:0.80
\end{tabular}




\subsection{Progress}

The upkeep period for HMS Richmond the First of Class (FoC) for the PGMU fit commenced in September 2017. By the time of the conference, it is expected that equipment Setting to Work (STW) and Trials will be underway but at the time of writing, progress includes:

- The completion of equipment removals. This has allowed a clear view of the affected spaces for the first time in almost 25 years;

- Structural surveys by Lloyd's, resulting in a large package of structural repairs that befits the age of the vessel and her planned life;

- The machinery spaces have been blasted and primed;

- Major equipment seatings have been installed, as have the majority of walkway supports;

- The installation of pre-manufactured pipe systems;

- A significant number of electrical glands have been installed ready for cabling.

To put the size of this A\&A into perspective, PGMU aims to install $12 \mathrm{~km}$ of pipework (with almost 1,250 flanges) and $15 \mathrm{~km}$ of wiring into the ship. The Installation Solution (IS) almost numbers 2,500 drawings.

\section{Construction \& Structure}

\subsection{Structural Design}

From a structural perspective, PGMU has made very few changes to the original structure in order to limit the cost and complexity of the project, there are however minor structural changes such as new mezzanine decks to provide greater accessibility to equipment. Previous studies were undertaken which confirmed that the supporting structure for both decks have sufficient margin of strength to withstand any additional loadings proposed by PGMU.

The major equipment seats were replaced or modified as follows

- $\quad$ DG seat in the UAMR - Completely replaced

- MG seat in the UAMR - To remain

- $\quad$ DG seat in the FAMR - Extensions to be fabricated and applied to the original seats

- $\quad$ MG seat in the FAMR - To be completely replaced and lowered within the compartment.

The FAMR DG seat is portrayed in Figure 3 with the extensions shown on either end.

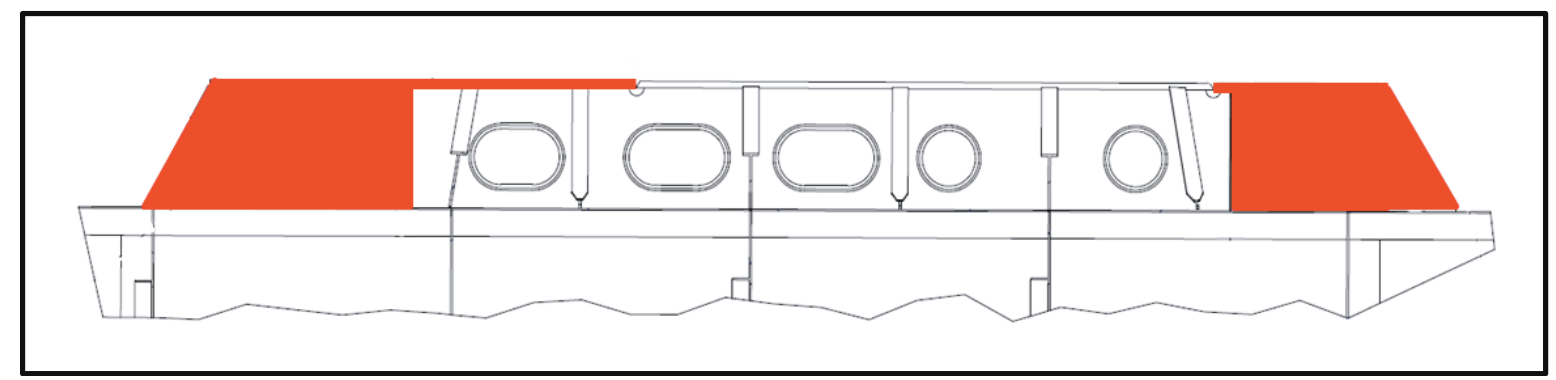

Figure 3 - FAMR DG Seat Extensions

\subsection{UAMR MG Seat}

The MG seat in the UAMR was intended to remain in situ as the only major seat not to be changed or extensively modified; however, following a flatness check, it became apparent the seat was too "wavy". To make the top face of the MG seat true to the necessary tolerances would require machining to such a degree that would reduce the thickness of the seat in places beyond the minimum thickness required to support and provide the necessary stiffness to the MG. The obvious solution would be to replace the seat in its entirety; however this would involve a very significant amount of Work In Way (WIW) that would impact on programme. The best of the considered solutions was to apply a doubler plate matching the footprint of MG raft that would sit on the seat. This is not best practice and further investigations will be undertaken in due course to determine an alternative approach if the same issue is encountered for the $2^{\text {nd }}$ fit of PGMU. 


\subsection{Different Design Houses}

Working with 2 different design houses also presented its own constructive challenges; although complying with the same rules, Babcock \& BAE were initially applying differing local standards to design and manufacture. Early examples were identified and workshops held that largely eradicated these discrepancies, however the project has learnt from 2 particular examples of this nature:

\section{- $\quad$ Pipe manufacture.}

- Babcock (UAMR) designed their pipework to tight tolerances with the expectation that production would use Computer Numerical Control (CNC) to aid manufacture of the majority of pipe sections. This was achievable because the UAMR was to be completely gutted providing Babcock with a blank canvas.

- BAE (FAMR) used larger tolerances with the plan to wire template a number of pipes in tight and/or complicated spaces.

Each solution has their advantages and disadvantages but incorporating both within the same IS proved an understandable issue for the production team.

- Manufacturing processes; specifically weld procedures. Through the IS, BAE instructed Babcock Production to carry out specific welds that were not in the weld specification library for Babcock in Devonport. Whilst it was perfectly possible to develop the appropriate procedures, it would have taken a significant amount of time in order to establish, validate and legalise. It was therefore decided it was quicker and cheaper to amend the IS to reflect the suite of weld specifications already in use with Babcock. Following this route, the resultant impact to Production was minimal with the detail noted for future Learning From Experience (LFE).

\subsection{Validation of Composite Flanges ${ }^{I}$}

Considered a big win for the project was the introduction and fit composite pipe flanges. Despite existing on the vessel in a number of legacy systems, the use of these flanges on LPSW systems was not permitted in accordance with Defence Standards (DEFSTAN) due to shock withstand, however the potential cost savings of using these couplings as identified by production led the DA to investigate further. It was highlighted that a typical fixed flange would cost 3 times more than a composite alternative and given the large quantity (some 1250 flanges) being fitted the savings possible were substantial.

Following liaison with the Naval Authority Group (NAG) a test plan was designed involving the fabrication of a test rig to undergo a series of shock tests at a QinetiQ facility in Scotland. This test rig was designed to be fitted with a range of pipes assemblies including both fixed flanges and composite flanges fitted to pipes covering a range of sizes of interest to the project. The shock test was attended by the DA and slow motion film of the test was undertaken, following a review of the test material the shock test was deemed successful allowing the endorsement of the NAG and the DA to fit the composite pipe flanges as part of PGMU. Following this test it is envisioned that these savings can be continued into future projects involving the RN.

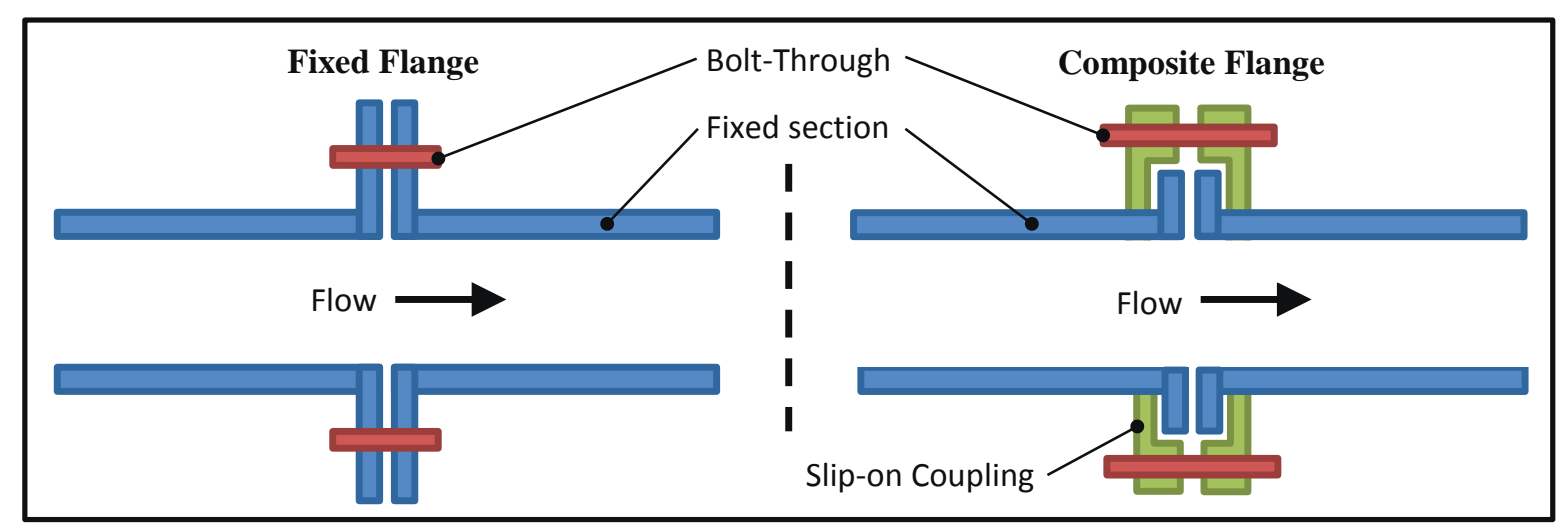

Figure 4 - Cross-Section of Fixed \& Composite Flanges

\footnotetext{
${ }^{1}$ The term 'composite flange' is misleading; it suggests the flange is comprised of multiple materials. In this context, it actually means that the flange is made up of multiple components and is better coined a 'slip-on flange'.
} 


\subsection{Cable Glands}

Another constructive challenge that the project has had to contend with is the problems associated with running new cables through the ship. The project has tried to minimise any disturbance to the original cables in an effort to avoid any significant cost that could potentially arise from damaging cables that have been in situ since build. The project has also tried to minimise the requirement for new glands in watertight bulkheads, however, the two aims have, at times, conflicted with each other. Overall, the PGMU project is installing or affecting a total of 56 glands of varying sizes.

Glands have come a long way since the time when the T23s were first built, see Figure 5 below; the old method involved building a steel frame around the cables and pouring a sealer into the cavity to set around the cables and (in theory) provide a watertight boundary between the compartments. Repairing such glands generally involved building up the frame and adding more sealant. Recently, trials have successfully been conducted which involved digging out the sealant to allow new cables to be run through the existing glands however this has not always been viable.

There is one specific gland in the original build of the class that is notorious for leaking across the fleet, the problem with this particular gland is that it provides the transition in the deck between the UAMR \& switchboard space below. Leaking glands can be detrimental to a vessel in many ways but this issue was compounded further as this particular gland leaked directly onto switchboards introducing a series of additional hazards to ship staff and the operation of the class.

Due to the severity of the risk the DA took the initiative and made efforts to correct the issue and it was planned to cut out the old gland and replace it with a new Multi-Cable Transit (MCT) Brattberg gland ${ }^{2}$. This gland is fitted into a cofferdam to encompass the area where the redundant fitting used to be. This cofferdam now forms part of the primary structure in accordance with Lloyd's Naval Rules (LNR) and is subject to the most stringent certification from the perspective of both design and production.

Whilst attempting to excavate the old gland a number of cables were damaged in the process, in part, due to the cables not having been set straight at build. Despite best efforts, the attempt was abandoned with the old gland being even less watertight than before. As such the cofferdam / Brattberg approach has been continued to secure the old (but intact) cables with a $2^{\text {nd }}$ new Brattberg being installed in the deck to carry the new PGMU cables and the replacements for the cables damaged during the excavation attempt.

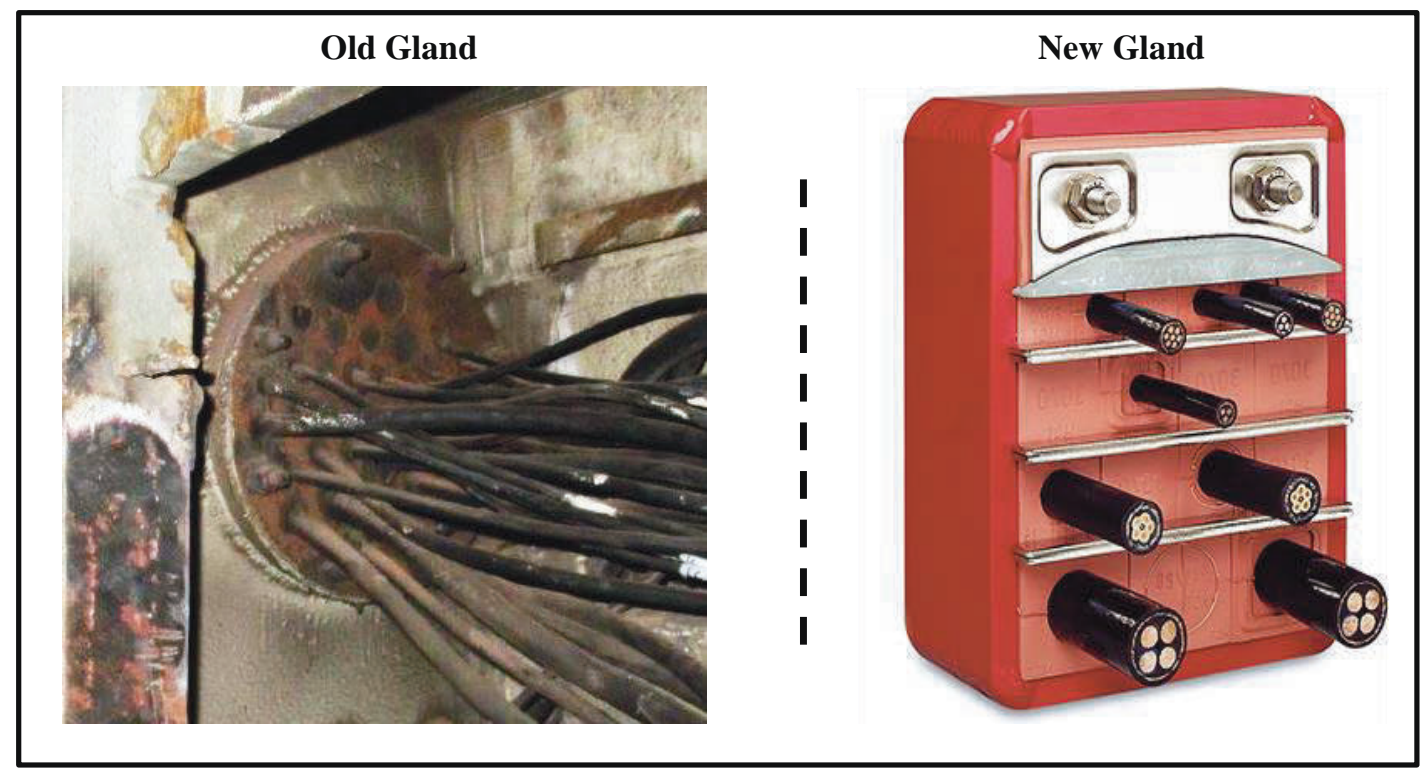

Figure 5 - Gland Comparison (generic)

\footnotetext{
${ }^{2}$ An MCT-Brattberg is a new design of gland that offers flexibility; the gland is modular and supports the capacity to increase the size and number of penetrations with relative ease.
} 


\subsection{Removal of the FAMR DG Rafts}

Each DG in the FAMR is supported by an intermediate raft that integrates between the DG mounts and their seat. This raft weights $15.5 \mathrm{t}$ and needed to be extracted from the space to allow the installation of the new DG and raft.

Production intended on cutting the DG rafts in situ and to then remove them piecemeal; 4-6 pieces, however it became apparent that they were fully galvanised; this zinc coating was not detailed in any extant T23 documentation and was therefore not expected. This resulted in Health \& Safety (H\&S) complications associated with the hotwork necessary to cut the rafts. Because of the zinc Production staff were required to wear specialised Personnel Protective Equipment (PPE) and to carry out the work in the absence of other tasking within the space, introducing additional cost and delays to the project.

In response to this issue and in a bid to avoid this problem for subsequent ships, a paper was commissioned which investigated the removal of these rafts as a single unit. This paper proved that this was possible and that deckhead within the space was sufficient to hang the rafts from, it also provided additional evidence to support the installation of the new rafts.

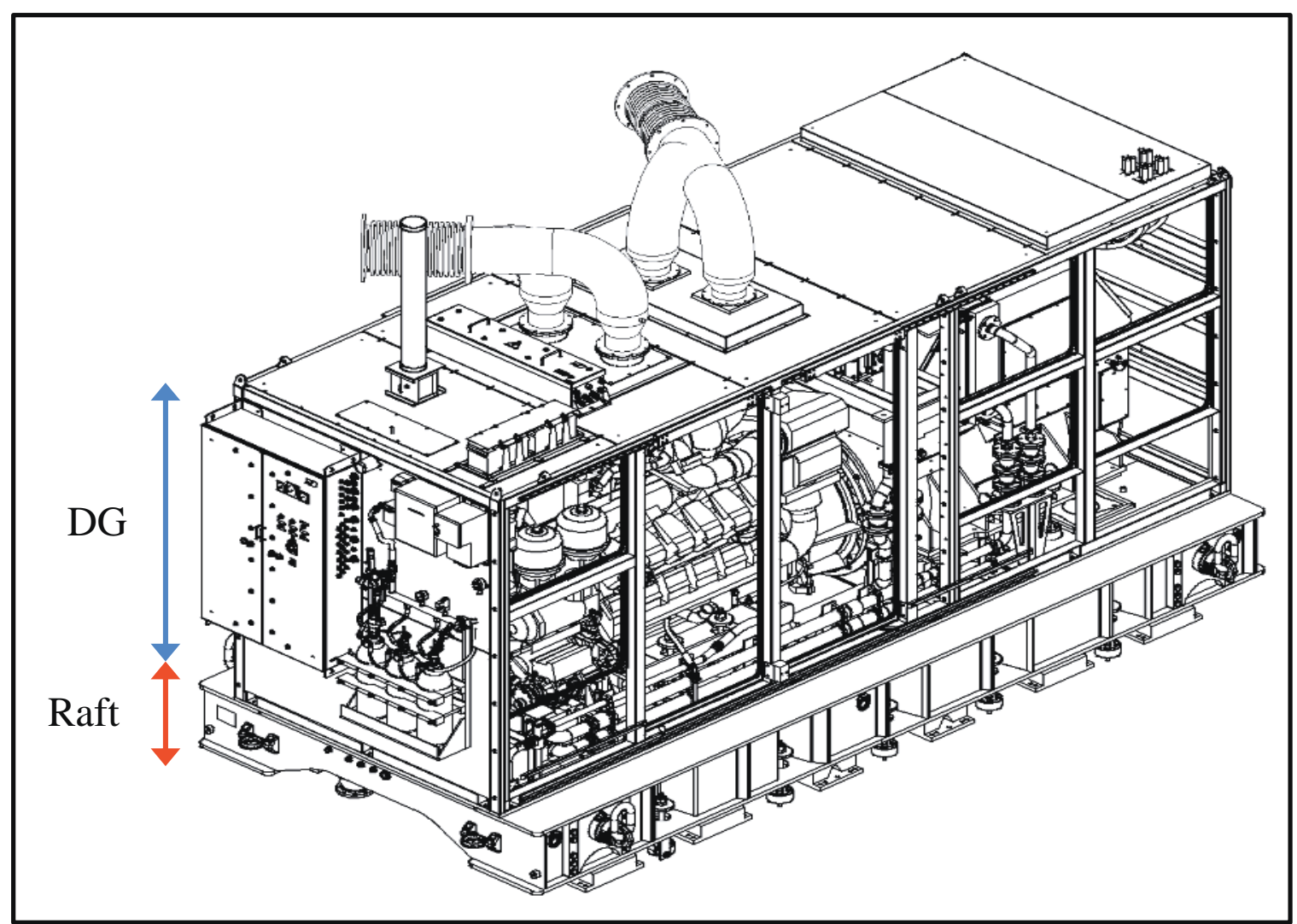

Figure 6 - Diesel Generator \& Raft 


\section{Managing Weight \& Stability}

\subsection{Weight \& Stability Targets}

In terms of stability the project were issued 2 particular system requirements:

\section{The system shall not increase the total ship weight}

2. The system shall not compromise platform stability

\subsubsection{Total Weight Target}

Not long into the project it became clear that achieving the first requirement was unrealistic and that the new, more powerful DGs would be significantly heavier. This is contrary to engineering principals which would assume that faster spinning engines are smaller and lighter. This owes largely to the heavier Generator half of the DG as well as new supporting items associated with a more modern, cleaner engine.

Upon this realization a maximum mass increase target figure of $40 \mathrm{t}$ was conceived, this was at a time when the project was largely unaware of what equipment would fit the system requirements. Because of this some rudimentary estimates were made which allowed for a $25 \%$ increase in mass to all equipment initially known to be replaced as part of PGMU.

This could be broken down as:

1. $5 \mathrm{t}$ per DG set;

2. 2 t per MG set;

3. 16t to cover changes to other items including but not limited to:

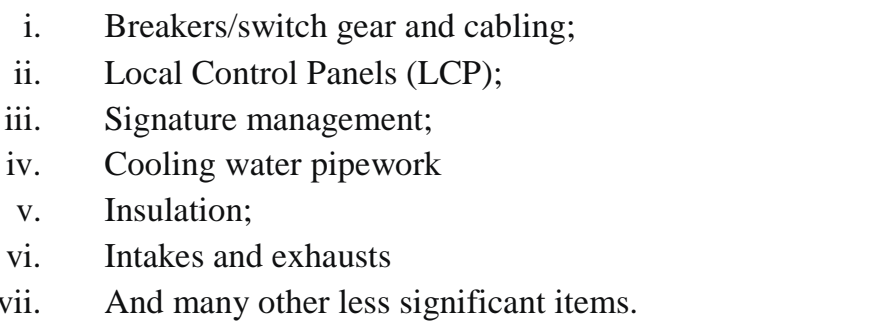

\subsubsection{Platform Stability Target}

With regards to the second requirement, the project took it upon themselves to improve stability by any reasonable means. Ships grow heavier with age, their Vertical Centre of Gravity (VCG) increases and they become less stiff and their response to sea motions will become sluggish. The T23s were first designed with an acceptable band of VCG in mind. They were built to the lower (stiff) end of this band and as they grow with age they would reach the upper (tender) end, this range being the stability margin of the class. Now the T23s are nearing their EOL, this stability margin is nearly spent and platforms run the risk of having Liquid Loading Restrictions $^{3}$ (LLR) imposed on them by the NAG of the MoD.

In response the PGMU project aims to take advantage and exploit the wholescale changes to the mass-dense PGMU items and improve the stability where possible. This has been achieved in a number of ways, some highlighted by:

1. Lowering the position of the FAMR MG, depicted in Figure 7

2. Minimise the mass of the items in the UAMR

3. Limiting mass in the funnel \& foremast

4. Increase the mass of the FAMR DG rafts

5. Reduction of lub oil tank size in UAMR in response to improved oil consumption

\footnotetext{
${ }^{3}$ LLR are imposed on platforms in order to ensure that they are kept within safe operating limits by reducing the quantity of liquid stores allowed onboard.
} 


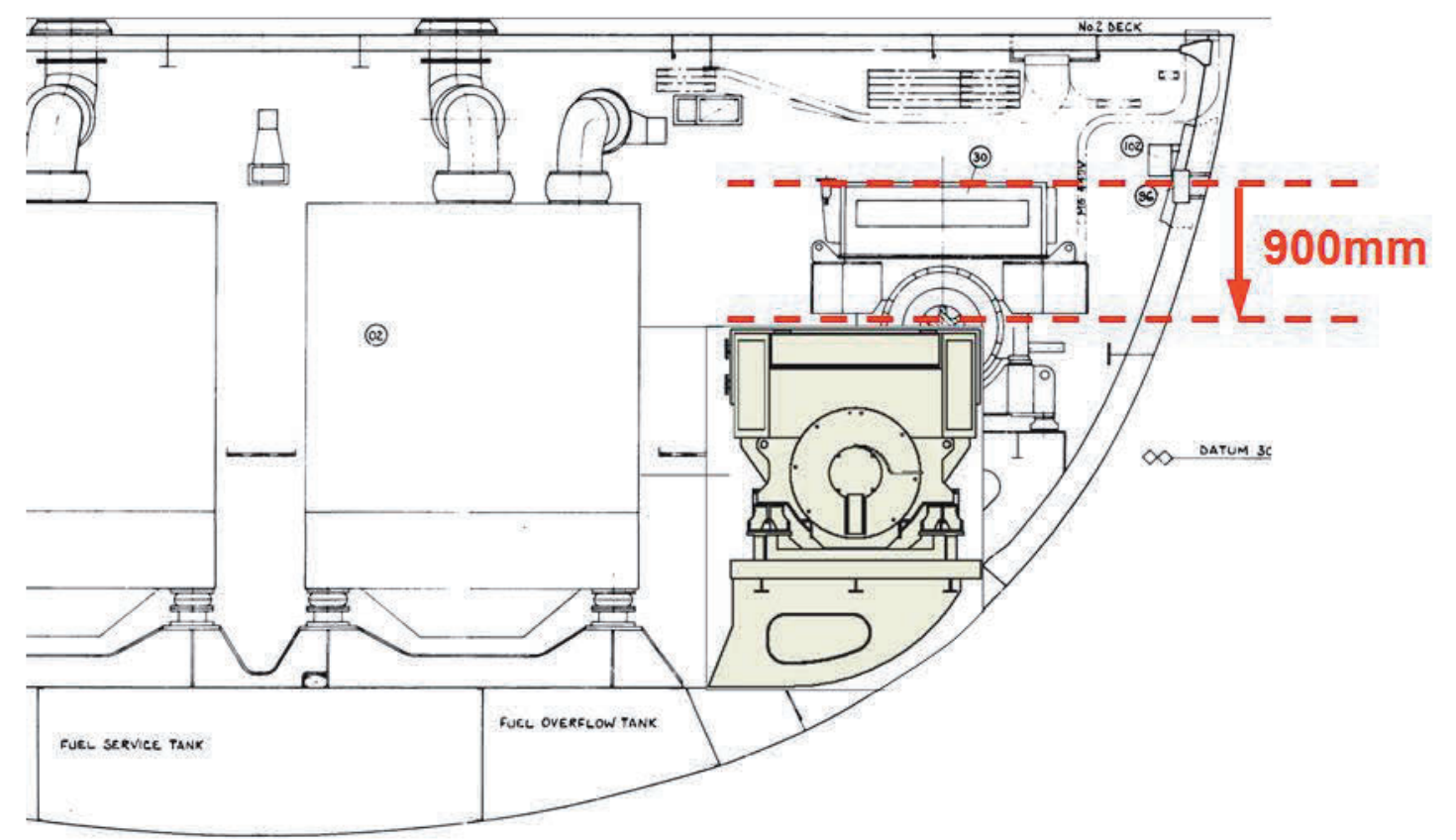

Figure 7 - FAMR Cross-Section showing MG Height Reduction

\subsection{CoG Sensitivity}

By referring to Figure 2, it is clear to see that the UAMR sits above the platform CoG and the FAMR sits below the platform CoG; with the UAMR being $20 \%$ further away from the CoG than the FAMR. Therefore any mass increase in the UAMR will have a greater impact on the stability of the vessel than the same mass increase in the FAMR. For example, if a certain mass positioned centrally in the FAMR were to inhibit a $1 \mathrm{~mm}$ reduction in VCG, the same mass in the UAMR would result in a $1.2 \mathrm{~mm}$ increase in VCG. This shows that managing weight and stability is not a simple task and we cannot make like for like changes without detrimentally effecting ship stability; more had to be done.

Despite all this it's in the Foremast and Funnel where the biggest impact to stability will be seen, but it is also the area in which the project has least control over in terms of stability. This stresses the need to make a positive impact in either of the AMRs.

The changes that are being undertaken in the Ship Control Centre (SCC) \& both Switchboard Rooms are negligible with regards to stability impact.

\subsection{Impacts to Stability}

\subsubsection{FAMR MG Seat Re-site}

One of the biggest gains in stability stems from the lowering of the FAMR MG seat to a lower position in the compartment. The new MG set is sizeable; it spans 6 longitudinal frames and has a mass of 15tonnes. It was clear to the DA there were potential stability gains surrounding this mass-dense item. It was initially hoped that the MG seat could be lowered within the FAMR compartment by $1 \mathrm{~m}$, but to reduce the vertical height of the seat would also involve bringing the item inboard within the confines of the hull. This was not possible without compromising walkway width and compliance to the Allied Naval Engineering Publication (ANEP) 77; it was therefore only possible to reduce the height of the MG seat by $900 \mathrm{~mm}$, Figure 7. 


\subsubsection{UAMR MG Seat Doubler Plates}

Whilst the project endeavoured to design in as much stability improvement as possible, it has subsequently eroded as the project progressed and encountered problems associated with the material state of the ship. As mentioned in section 2.2, the UAMR MG seat required doubler plates to be fitted in order to avoid significant WIW. An additional complication to the problem is that these doublers plates weigh an additional $300 \mathrm{~kg}$. This results in an additional $300 \mathrm{~kg}$ to a position high above the $\mathrm{CoG}$ of the class; this is a prime example of the complications regarding platform material state effecting project cost, management and ship operation.

\subsubsection{Increase in Mass of FAMR DG Rafts}

As first noted in 2.6 \& depicted in Figure 6, the FAMR DG rafts have been re-designed with a significant benefit to stability improvement. As these rafts are some of the lowest positioned items across the whole ship, increasing the mass of these already heavy items provided a very positive and simple gain in terms of reducing overall vessel VCG. Another noteworthy benefit of increasing the mass of the rafts is the greater attenuation of noise from the DGs.

\subsubsection{Removal of the Special Service Air System (SSAS - commonly known as Masker)}

The Masker air system was designed into the T23s as a means to alter or 'mask' the underwater signature of the platforms, its effectiveness however is questionable and it has been virtually unused in service for many years whilst still requiring regular and expensive overhaul during upkeep periods. The benefits of removing the compressors were also considered to be key to the redesign of the UAMR and to allow the fit of new PGMU equipment.

From a stability perspective the impact of the removal of the SASS is significant as seen in Table 3. Whilst the drop in VCG is highly advantageous when large new generators are being fitted in the UAMR, the change to Transverse Centre of Gravity (TCG) could have resulted in the ship developing a list. To address this impact the design featured re-sites of various equipment to counteract this shift in TCG such as; re-siting of HP air bottles; a Lub Oil (LO) tank; a watertight door and other miscellaneous items.

Table 3 - Stability Impact of Masker Removal

\begin{tabular}{crl}
\hline Impact to... & Delta, $\boldsymbol{\Delta}$ & \multicolumn{1}{c}{ Units } \\
\hline VCG & -8.00 & $\mathrm{~mm}$ \\
$T C G$ & 10.00 & $\mathrm{~mm}$ \\
Displacement & 10 & tonnes \\
\hline
\end{tabular}

\subsection{Stability Conclusion}

Managing the weights and stability of PGMU has been a high priority throughout the design phase and continues to have an impact on decisions being undertaken through production. Considering all the changes that have been made as part of PGMU, the project expects to reduce the CoG by a healthy figure equivalent to about 4.5 years' worth of ship growth. This stability improvement will support the ships as they continue into service past their original design life with LLR which would otherwise be worse otherwise.

\section{Conclusion}

This paper has noted just some of the challenges that the PGMU project has faced during the FoC fit of a major update to the class of T23s. The presentation delivered to the conference will aim to provide greater detail, touch on points and LFE missed within this paper as well as items that have been identified since it's time of writing. 


\section{Acknlowdgements}

The author is very grateful to colleagues within the NDP team, DMS, the PGMU Production Team \& Lot 5 from Babcock for their support and efforts to the delivery of PGMU.

\section{References}

1. ANEP 77 - Naval Ship Code, NATO, August 2014

2. Facing the challenges of integration and physical constraints when replacing major equipment in old platforms. D. Bainbridge, S. McCance, 2016.

3. National Shipbuilding Strategy, UK MoD, September 2017

4. System Integration Challenges of Deliverng a Power System Update to Type 23 Class, S. Hilder, W. Roberts, June 2017

5. The Royal Navy's new frigates and the National Shipbuilding, House of Commons, February 2017 